\title{
OMAH MANGROVE: PENDEKATAN ARSITEKTUR LINGKUNGAN DAN LOKALITAS DALAM PERANCANGAN ECOWISATA MANGROVE DI MUARA ANGKE
}

\author{
Matthew Louis ${ }^{1)}$, Diah Anggraini ${ }^{2)}$ \\ 1) Program Studi S1 Arsitektur, Fakultas Teknik, Universitas Tarumanagara, matthewlouis7@gmail.com \\ 2) Program Studi S1 Arsitektur, Fakultas Teknik, Universitas Tarumanagara, diaha@ft.untar.ac.id
}

\begin{abstract}
Abstrak
Hutan mangrove merupakan salah satu habitat dan sekaligus pemegang peranan penting dalam ekosistem pantai. Hutan mangrove sendiri merupakan rumah bagi beberapa jenis biota laut. Berdasarkan data kehutanan di Indonesia terdapat sekitar 3.489.140,68 Ha. Hutan mangrove terbesar terdapat di wilayah Sumatera. Di Jakarta Hutan mangrove terdapat di Jakarta Utara tepatnya di sekitar daerah Kapuk hingga Muara Angke. Luasan ekosistem 291.17 ha dengan tingkat kerapatan sebesar 272,79 ha (jarang) 16,83 ha (sedang) , 1,54 ha (lebat). Di Kapuk Muara sudah terdapat suaka margasatwa untuk hutan mangrove yang berada di Muara Angke. Namun meski demikian masih terdapat hutan mangrove dengan kategori rusak sebesar 272,9 ha dan 18,38 ha terkategori tidak rusak sehingga termasuk ke dalam kategori kritis. Keadaan ini diperburuk dengan kegiatan reklamasi yang baru berjalan sebagian sebagian. Nelayan kehilangan mata penchariannya dikarenakan umpan dan jaring nelayan tertimbun oleh urukan tanah reklamasi sehingga wilayak penangkapan ikan menjadi berkurang. Menurut tulisannya tentang teori lokalitas, Sutanto (2020) menyatakan bahwa arsitektur dalam perkembangannya harus memanfaatkan teknologi yang berkelanjutan. Hal ini menjadi penting dalam membangun sebuah tradisi baru yang dapat memberikan kegunaan terhadap penggunanya. Pendekatan lokalitas ini diharapkan dapat membantu masyarakat nelayan di Muara Angke menghadapi permasalahan mereka. Selain itu studi ini juga mengacu pada metode enviromental architecture, yang menghargai lingkungan dan ciri lokalitas masyarakat setempat yang membentuk kawasan Muara Angke. Tujuan studi adalah menghasilkan konsep penataan area restorasi mangrove, sekaligus dapat meningkatkan kesejahteraan nelayan di lokasi tersebut.
\end{abstract}

Kata kunci: Arsitektur Lingkungan ; Lokalitas ; Ekowisata,; Mangrove

\begin{abstract}
Mangrove forest is one of the habitats and at the same time the holder of an important role in the coastal ecosystem. Mangrove forest itself is home to several types of marine life. Based on forestry data in Indonesia, there are around $3,489,140.68 \mathrm{Ha}$. The largest mangrove forest is in Sumatra. In Jakarta, there are mangrove forests in North Jakarta, precisely around the Kapuk to Muara Angke areas. The ecosystem area is 291.17 ha with a density level of 272.79 ha (rare) 16.83 ha (medium), 1.54 ha (heavy). In Kapuk Muara there is already a wildlife sanctuary for the mangrove forest in Muara Angke. However, there are still mangrove forests with a damaged category of 272.9 ha and $18.38 \mathrm{ha}$ categorized as undamaged so that they are included in the critical category. This situation is exacerbated by the reclamation activities which have only been partially implemented. Fishermen lose their livelihoods because the bait and fishing nets are buried by reclaimed land so that the fishing area is reduced. According to his writings on locality theory, Sutanto (2020) states that architecture in its development must utilize sustainable technology. This becomes important in building a new tradition that can provide usefulness to its users. This locality
\end{abstract}


approach is expected to help the fishing communities in Muara Angke deal with their problems. In addition, this study also refers to the environmental architecture method, which respects the environment and local characteristics of the local community that make up the Muara Angke area. The purpose of the study is to produce a concept of structuring a mangrove restoration area, as well as to improve the welfare of fishermen in that location.

Keywords: Environmental Architecture ; Locality ; Ecotourism,; Mangroves

\section{PENDAHULUAN}

\section{Latar Belakang}

Hutan mangrove merupakan salah satu faktor penting dalam ekosistem pantai di Jakarta Utara, yang antara lain berfungsi sebagai tempat tinggal hewan dan anemon laut lainya. Artinya juga memudahkan nelayan dalam memancing ikan. Hutan mangrove juga berfungsi sebagai sebagai pemecah ombak. Di Jakarta Utara terdapat hutan mangrove dengan luasan ekosistem 291.17 ha dengan tingkat kerapatan sebesar 272,79 ha (jarang), 16,83 ha (sedang), dan 1,54 ha kondisi lebat. Kapuk Muara sudah memiliki kawasan suaka margasatwa untuk hutan mangrove yang berada di Muara Angke. Namun meski demikian kondisi hutan mangrove di kawasan tersebut masih terkategori rusak sebesar 272,9 ha dan 18,38 ha terkategori tidak rusak (termasuk ke dalam kategori kritis). Keadaan ini diperburuk dengan kegiatan reklamasi pantai yang saat ini berjalan sebagian sebagian. Nelayan kehilangan mata pencahariannya dikarenakan umpan dan jaring nelayan tertimbun oleh urukan tanah reklamasi sehingga wilayah penangkapannya menjadi berkurang. (Taufik Ridwan, AntaraNews ,2021)

\section{Rumusan Permasalahan}

a. Bagaimana agar keberadaaan fasilitas ekowisata mangrove dapat mendukung upaya restorasi hutan mangrove di Muara Angke?

b. Bagaimana pendekatan arsitektur lingkungan dan pertimbangan aspek lokalitas dapat menghasilkan perancangan fasilitas ekowisata yang dapat meningkatkan kesejahteraan masyarakat nelayan di kawasan restorasi hutan mangrove?

\section{Tujuan}

Tujuan dari studi ini adalah untuk menghasilkan konsep perancangan ekowisata yang dapat mendukung upaya restorasi hutan mangrove, sekaligus dapat meningkatkan kesejahteraan warga nelayan di Muara Angke.

Keberadaan ekowisata mangrove dapat memberikan edukasi kepada masyarakat luas tentang pentingnya hutan mangrove dalam ekosistem pantai di Muara Angke.

\section{KAJIAN LITERATUR}

\section{Hutan Mangrove}

Ekosistem mangrove berperan penting dalam mendukung kehidupan organisme yang terdapat di dalamnya. Fungsi hutan mangrove dibedakan ke dalam tiga macam, sebagai berikut:

a. Fungsi fisik :

- Menjaga garis pantai dan tebing sungai dari erosi/abrasi agar tetap stabil

- Mempercepat perluasan lahan

- Mengendalikan intrusi air laut

\section{b. Fungsi ekonomi :}

- Merupakan penghasil kayu sebagai sumber bahan bakar (arang, kayu bakar), bahan bangunan (balok, atap rumah, tikar) 


\section{c. Fungsi biologi :}

- Merupakan tempat mencari makan (feeding ground), tempat memijah (spawning ground) dan tempat berkembang biak (nursery ground) berbagai jenis ikan, udang, kerang dan biota laut lainnya.

\section{Ekowisata}

Ekowisata lebih populer dan banyak dipergunakan dibanding dengan terjemahan yang seharusnya

dari istilah ecotourism, yaitu ekoturisme. Terjemahan yang seharusnya dari ecotourism adalah wisata ekologis. Yayasan Alam Mitra Indonesia (1995) membuat terjemahan ecotourism dengan ekoturisme. Namun dalam tulisan ini dipergunakan istilah ekowisata yang banyak digunakan oleh para rimbawan. Hal ini diambil misalnya dalam salah satu seminar dalam Reuni Fakultas Kehutanan Universitas Gadjah Mada (Fandeli, 1998). Kemudian Nasikun (1999), juga mempergunakan istilah ekowisata untuk menggambarkan adanya bentuk wisata yang baru muncul pada dekade delapan puluhan (Irwan,2020).

Manfaat ekowisata berdampak dalam berbagai aspek. Manfaat tersebut meliputi aspek konservasi, pemberdayaan dan pendidikan lingkungan. Manfaat tersebut secara lengkap adalah sebagai berikut: (Irwan,2020).

a. Konservasi : Keterkaitan ekoturisme dan satwa terancam punah sangat erat, bahkan harus bersifat positif, sebagaimana studi yang dilakukan oleh peneliti Universitas Griffith. Wisata berkorelasi positif dengan konservasi berarti memberikan insentif ekonomi yang efektif untuk melestarikan, meningkatkan keanekaragaman hayati budaya, melindungi warisan alam serta budaya di planet bumi.

b. Pemberdayaan ekonomi : ekoturisme melibatkan masyarakat lokal berarti meningkatkan kapasitas, kesempatan kerja masyarakat lokal. Konsep eko-wisata adalah sebuah metode yang efektif untuk memberdayakan masyarakat lokal di seluruh dunia guna melawan kemiskinan, mencapai pembangunan berkelanjutan.

c. Pendidikan lingkungan: Melibatkan pendidikan lingkungan berarti kegiatan wisata yang dilakukan harus memperkaya pengalaman, juga kesadaran lingkungan melalui interpretasi. Kegiatan harus mempromosikan pemahaman, penghargaan yang utuh terhadap alam, masyarakat, budaya setempat.

Oleh karena itu, menurut Irwan (2020), berdasarkan tiga komponen penting tersebut, maka tidak secara otomatis setiap perjalanan wisata alam merupakan aktifitas wisata berbasis ekologi atau ecotourism.

\section{Enviromental Architecture}

Menurut N.H.T Siahaan dalam buku Hukum Lingkungan dan Ekologi Pembangunan (2004) yang dikutip oleh Vanya Karunia pada tahun 2021.Latar belakang konsep Ekologi Arsitektur adalah kerusakan lingkungan, sehingga mengakibatkan perubahan iklim, krisis energi dan tuntutan kualitas hidup manusia. Konsep desain arsitektur memiliki kecenderungan untuk beradaptasi dengan lingkungan melalui berbagai pendekatan dalam metode desain. Orientasi pergeseran pembangunan untuk ramah lingkungan juga merupakan tuntutan dari pembangunan berkelanjutan yaitu konservasi lingkungan yang sebelumnya mengabaikan dampak perubahan iklim. Regulasi pembangunan berwawasan lingkungan menjadi metode perancangan yang tidak hanya berskala regional, namun juga skala nasional hingga internasional. Konsep Ekologi Arsitektur adalah konsep membangun yang memperhatikan keseimbangan lingkungan alam dan buatan dengan unsur utama manusia, bangunan dan lingkungan (Kompas.com, 2021). 
bangunan dan lingkungan secara harmonis. Perancangan berkonsep Ekologi Arsitektur merupakan perencanaan yang bertujuan mendesain sistem yang mampu menjaga simbiosis lingkungan dengan bangunan sehingga tidak membebani siklus alami. (Kompas.com, 2021)

Metode perancangan arsitektur berbasis ekologi, mengidentifikasi potensi dan kendala iklim tropis dalam perancangan pembangunan dan menentukan unsur pendekatan analisis berbasis ekologis yang dapat disistematiskan sebagai strategi metode desain pembangunan berkelanjutan dalam pengelolaan atau manajemen iklim untuk mencapai konservasi dan pelestarian alam di iklim tropis. (Kompas.com, 2021)

\section{Teori Lokalitas}

Teori lokalitas merupakan sebuah gerakan yang memperjuangkan identitas kelokalan di tengah arus globalisasi. Lokalitas bergerak dan hidup dalam serangan modernitas dan gelombang globalisasi, yang akhirnya membuat nilai-nilai kokal terpinggirkan. Namun dalam perkembangannya, ketika dunia menjadi begitu menjadi modern dan universal, kerinduan akan nilai-nilai kelokalan masih terus digali dan dicari serta dianggap sebagai kekuatan keruangan yang memiliki aura identitas dan karakter sebuah tempat. Menurut Sutanto (2020) sebagai sebuah gerakan, lokalitas mengusung dua narasi besar di dalamnya yaitu vernakular dan tradisional. Pertama, vernacular yang dalam Bahasa Latin berarti vernaculus memiliki arti asli, pribumi, original, nasional, domestik . Vernaculus berkaitan dengan pengertian penduduk asli yang memiliki dialek (logat) sebagai bahasa sehari-hari setempat. Kedua adalah tradisional yang memiliki akar kata tradisi yang berasal dari bahasa Latin traditionem, dari traditio yang berarti "serah terima, memberikan, estafet, mengirim, menyerahkan, memberi untuk diamankan". Ada sesuatu yang diberikan secara turun temurun (dari generasi ke generasi berikut) dan harus dijaga karena sebagai sebuah warisan yang memiliki arti khusus dari sebuah komunitas masyarakat. Kata vernacular dalam arsitektur, yaitu Arsitektur Vernakular pertama kali menjadi dikenal dan dipublikasikan oleh Bernard Rudofsky (1964) dalam bukunya Architecture Without Architects, An Introduction to Non-pedigreed Architecture yang menyatakan bahwa arsitektur vernacular dilahirkan tidak melalui siklus mode, terlihat abadi, tidak dapat diperbaiki, karena melayani tujuannya untuk kesempurnaan. Biasanya, menyediakan asal bentuk bangunan asli dan metode konstruksi hilang di masa lalu (disarikan dari Sutanto, 2020).

Menurut Lewis Mumford dan Liane Lefaivre (disarikan dari Sutanto, 2020), ada lima poin penting dalam memandang nilai lokalitas yaitu :

a. Lokalitas bukan hanya terpaku dari kebesaran atau nilai absolut dari sejarah.

b. Lokalitas adalah tentang bagaimana melihat bahwa seharus sebuah tempat memiliki sentuhan personal, untuk sebuah keindahan yang tidak terduga

c. Lokalitas dalam perkembangannya harus memanfaatkan teknologi yang berkelanjutan, dan ini menjadi penting dalam membangun sebuah tradisi baru.

d. Lokalitas harus memberikan kegunaan terhadap penggunanya, modifikasi terhadap lokalitas harus dibuat bukan hanya sekedar memenuhi kebutuhan.

e. Globalitas dan Lokalitas bukanlah sesuatu yang harus dipertentangkan tetapi mereka saling melengkapi

Dari lima poin penting ini, posisi lokalitas memiliki kompleksitas tinggi karena berhubungan dengan berbagai kondisi seperti menelaah sejarah dalam konteks waktu, atmosfir sebuah tempat, membuka diri terhadap teknologi, pengguna sebagai agen keruangan dan menyiasati globalitas sebagai bagian perkembangan. 


\section{Biomorphic Architecture}

Desain bangunan yang langsung dipengaruhi oleh hewan, tumbuhan, tubuh manusia dan struktur anatomi dengan bahan yang dipilih untuk menciptakan harmoni estetika. Arsitektur biomorfik menggunakan elemen eksisting alam sebagai sumber inspirasi untuk menciptakan bentuk. Struktur biomorfik di dalam arsitektur merupakan sistem struktur yang mengambil kolaborasi (kerjasama) antara manusia dengan alam sebagai dasar bentuk yang dipadukan. Struktur ini lahir dari pemikiran akan pentingnya berorientasi ke alam beserta lingkungannya. Biomorfik berpegang pada pendirian bahwa alam sendiri adalah konstruksi yang ideal dalam arsitektur. Penyaluran gaya yang terjadi tergantung dari bentuk dan prinsip kerja makhlukmakhluk alam, menjadi analogi dasar perencanaan (Hasya Pudjadi,2016).

Analogi arsitektur biomorfik diartikan bahwa arsitektur sebagai makhluk hidup atau arsitektur itu hidup. Jika arsitektur itu hidup maka arsitektur mengalami metabolisme yaitu tumbuh dan berkembang. Hal ini merupakan salah satu ciri makhluk hidup. Pertumbuhan dan perkembangan sebuah hasil karya arsitektur bisa direncanakan. Gagasan pertumbuhan tersebut bisa dilakukan secara vertikal atau horisontal. Jika perkembangan karya arsitektur tersebut tidak direncanakan maka perkembangannya bisa secara sporadis yaitu tidak beraturan. Bangunan adalah suatu proses biologis, bangunan bukan suatu proses estetika (Hasya Pudjadi,2016).

\section{METODE PENELITIAN}

Penelitian untuk menyusun konsep perancangan fasilitas ekowisata hutan mangrove mengacu pada pendekatan arsitektur ekologi. Sedangkan pemahaman terhadap aspek lokalitas dilakukan dengan melakukan investigasi secara mendalam terhadap kehidupan nelayan di lokasi penelitian, kondisi alam dan fisik lingkungan pantai yang menjadi lingkungan permukiman mereka serta mempelajari ekosistem pantai yang bekerja pada kawasan hutan mangrove di lokasi studi.

Desain bangunan dikembangkan dengan mengacu pada pendekatan biomorphic architecture yang dipengaruhi oleh hewan, tumbuhan, tubuh manusia, dan struktur anatomi dengan bahan yang dipilih untuk menciptakan harmoni estetika. Sesuai dengan pendekatan arsitektur biomorfik, yaitu menggunakan elemen eksisting alam sebagai sumber inspirasi untuk menciptakan bentuk. Analogi arsitektur biomorfik diartikan bahwa arsitektur sebagai makhluk hidup atau arsitektur itu hidup dan berkembang. Hal ini merupakan salah satu ciri makhluk hidup. Pertumbuhan dan perkembangan sebuah hasil karya arsitektur bisa direncanakan.

\section{Investigasi kawasan}

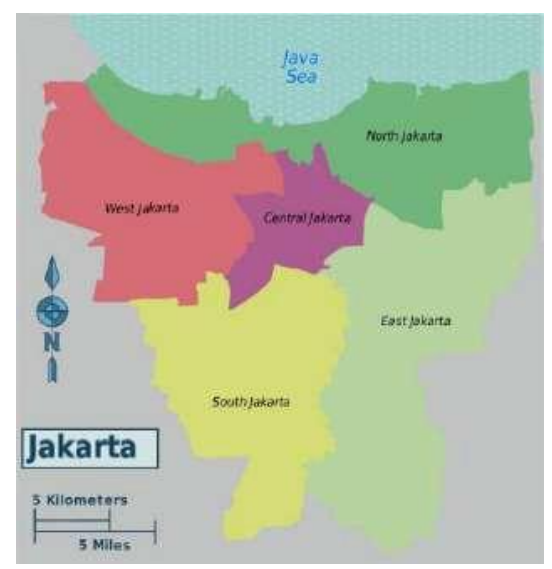

Gambar 1: Peta Kota Jakarta

Sumber : abundancethebook.com 2019 
Daerah Khusus Ibukota Jakarta (DKI Jakarta) adalah ibu kota negara dan kota terbesar di Indonesia. Jakarta terletak di pesisir bagian Pulau Jawa. Jakarta memiliki luas sekitar $664,01 \mathrm{~km}^{2}$ (lautan: 6.977,5 km²), dengan penduduk berjumlah 11.100 .929 jiwa (2020).Wilayah metropolitan Jakarta (Jabodetabek) yang berpenduduk sekitar 28 juta jiwa,merupakan metropolitan terbesar di Asia Tenggara atau urutan kedua di dunia. Sebagai pusat bisnis, politik, dan kebudayaan, Jakarta merupakan tempat berdirinya kantor-kantor pusat BUMN, perusahaan swasta, dan perusahaan asing. Kota ini juga menjadi tempat kedudukan lembagalembaga pemerintahan dan kantor sekretariat ASEAN. Jakarta dilayani oleh dua bandar udara, yakni Bandara Soekarno-Hatta dan Bandara Halim Perdanakusuma, serta tiga pelabuhan laut di Tanjung Priok, Sunda Kelapa, dan Ancol.(Wikipedia,2019)

\section{Muara Angke}

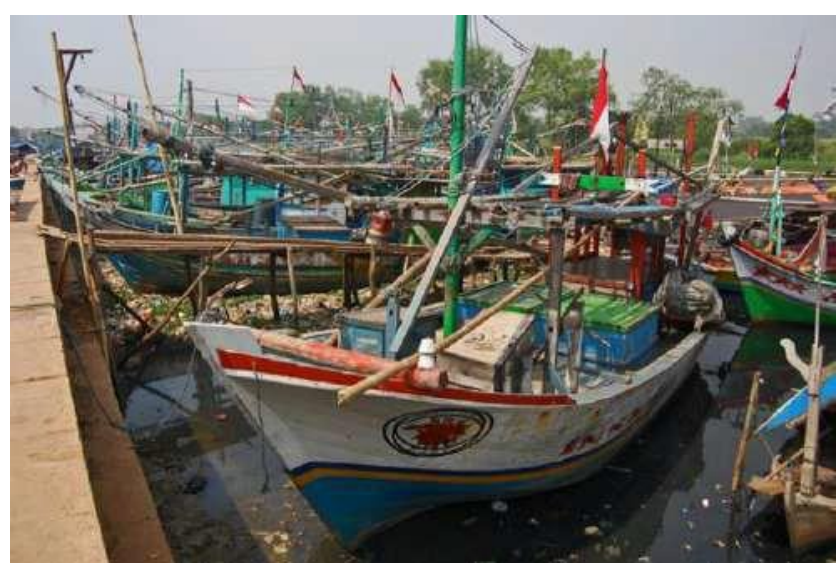

Gambar 2 : Parkir kapal Muara Angke Sumber : mediaindonesia.com 2019

Kawasan Muara Angke dikenal sebagai kampung nelayan yang berada di kawasan perikanan DKI Jakarta. Muara Angke memiliki pelabuhan perikanan yang terintegrasi dengan perumahan nelayan dan kantor pengelola pelabuhan perikanan milik pemerintah DKI Jakarta. Hampir seluruh masyarakat yang tinggal di Muara Angke menggantungkan hidupnya dari sektor perikanan, baik menjadi nelayan tradisional, Anak Buah Kapal (ABK), maupun nelayan pemilik kapal. Masalah utama di daerah ini adalah akibat dari adanya proyek reklamasi tahap 1 , yang mempengaruhi proses dan hasil penangkapan ikan para nelayan tradisional yang telah turun menurun tinggal di Muara Angke (Wikipedia, 2019).

\section{DISKUSI DAN HASIL}

Bentuk tapak berbentuk segitiga berada di ujung Muara Angke, berdampingan dengan Kali Adem, hutan mangrove, laut lepas, dan pemukiman penduduk (Gambar 3). 


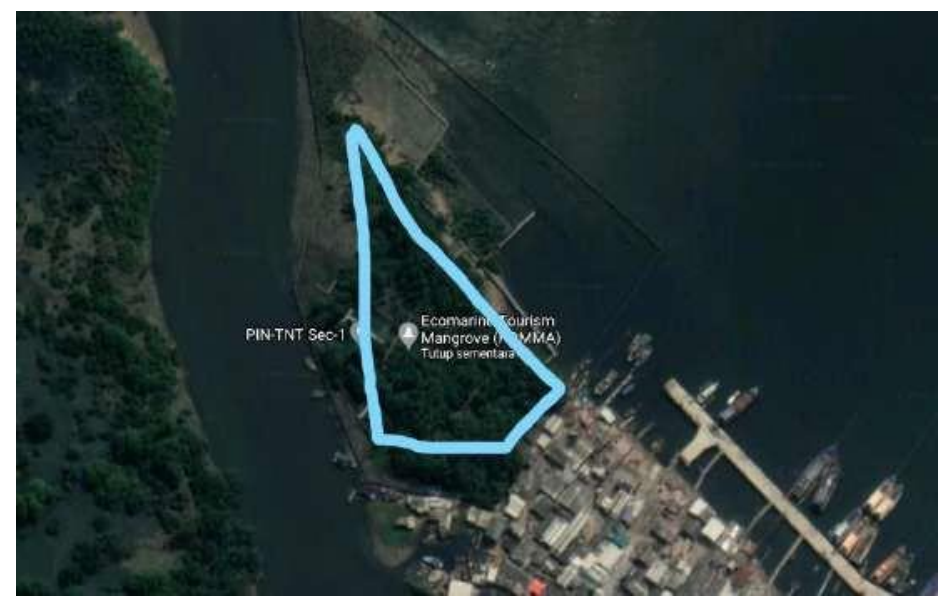

Gambar 3 : Lokasi Tapak Perancangan

Sumber : Google Maps , 2021

\section{ANALISIS TAPAK}

Lokasi tapak berada di Jalan Muara Angke, Pluit, Penjaringan, Pluit, Kec. Penjaringan, Jakarta Utara. Bentuk tapak berbentuk segitiga berada di ujung Muara Angke, berdampingan dengan Kali Adem, hutan mangrove, laut lepas, dan pemukiman penduduk (Gambar 3).

\section{Analisis SWOT pada tapak terpilih}

Tabel Analisis SWOT

\begin{tabular}{ll}
\hline Strength & $\begin{array}{l}\text { Tapak berada dekat dengan kampung nelayan Kapuk Muara. } \\
\text { Lokasi tapak berada di kawasan hutan mangrove yang langsung mengarah ke } \\
\text { laut lepas. }\end{array}$ \\
\hline Weakness & - Tapak merupakan area yang kumuh dan banyak sampah plastik berserakan \\
& - Lokasi tapak berada di permukiman yang padat dan jalan menuju ke tapak \\
& dari arah permukiman penduduk sempit sehingg akses untuk pengunjung sulit.
\end{tabular}

Opportunity - Tapak berada di dekat tempat parkir kapal nelayan, memudahkan aksesibilitas

kapal nelayan dan pengunjung dari arah laut menuju ke lokasi .

- Tapak terpili sebelumnya merupakan kawasan mangrove yang sudah tutup. Hal ini memberikan kesempatan untuk mengolah desain yang baru.

Threat Dengan keadaan tapak yang sangat padat membuat, sehingga perancangan proyek wisata mangrove harus mempertimbangkan dampak sosial ekonomi bagi penduduk setempat.

Tapak bersebelahan dengan Kali Adem yang menjadi muara berbagai sampah dari hulu/daratan. Sehingga memerlukan solusi yang tepat agar sampah tersebut tidak mengganggu aktivitas ecowisata yang direncanakan.

Sumber : Pribadi,2021 


\section{Analisis Program Kegiatan}
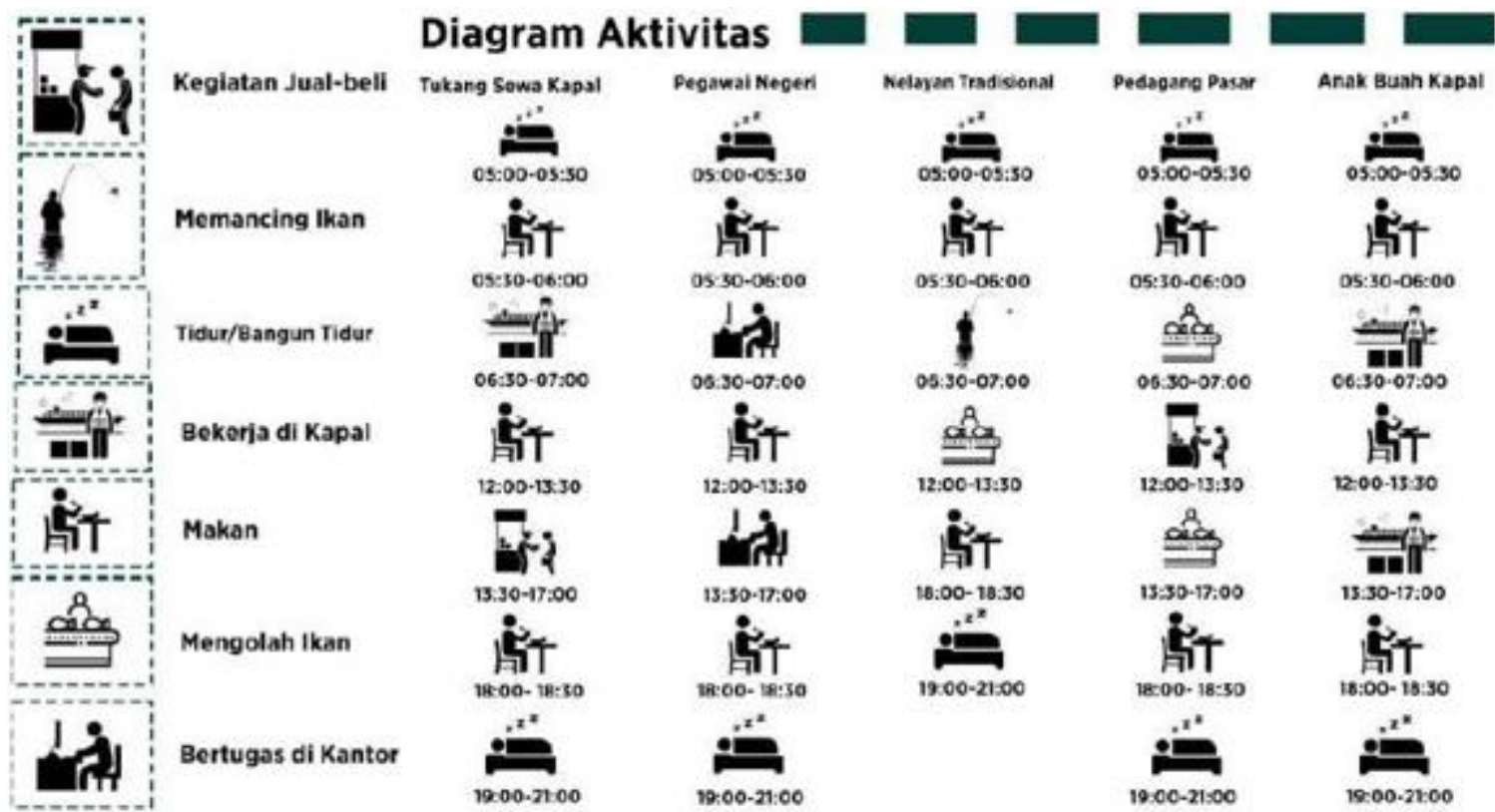

Gambar 4: Analisis Program Kegiatan

Sumber : Pribadi, 2021

\section{Pembahasan dan Hasil}

Perancangan Ecowisata Mangrove di Muara Angke menghasilkan wadah aktivitas konservasi dan wisata yang berdampak pada keberlanjutan ekosistem pantai dan peningkatan kesejahteraan nelayan. Program utama proyek merupakan wadah bagi eco marine research yang fokusnya adalah untuk membantu persebaran hutan mangrove agar tumbuh optimal dan terhindar dari sampah. Sekolah mangrove untuk mengoptimalkan manfaat ekowisata kepada masyarakat sekitar dengan memberikan pelajaran tentang interaksi dan pengembangan kawasan wisata kepada penduduk lokal Muara Angke. Intinya lebih kepada pelatihan mental dan interaksi penduduk lokal dalam menghadapi pengunjung. Targetnya terutama ke anakanak nelayan umur 10-18 tahun seperti pelatihan pertunjukan Nadran, pelatihan show supaya menarik minat pengunjung untuk menonton dan sebagainya. Sementara warga nelayan dewasa diberikan pelatihan pengelolan dan pemasaran produk ikan dan budi daya sampah, Tujuan kegiatan pengelolaan dan budi daya sampah terutama untuk mengurangi hambatan pertumbuhan mangrove dan menjaga kawasan lebih sehat dan higienis. Pengelolaan sampah lebih dalam bentuk pengumpulan dan pemilahan, yang kemudian dijual kepada pengepul sampah sebagai penghasilan tambahan warga.

\section{Konsep Tri Axis Dalam Perancangan Tapak.}

Konsep Tri Axis diambil dari lingkungan sekitar tapak yang membentuk 3 sumbu axis yang setiap sudutnya memiliki potensinya masing-masing. Tapak menghadap ke 3 arah yaitu laut, sungai, dan pemukiman penduduk. Zonasi pada tapak mengikuti pola segitga tersebut, menghasilkan zona konservasi, zona kerja , dan zona wisata dan komunitas. 


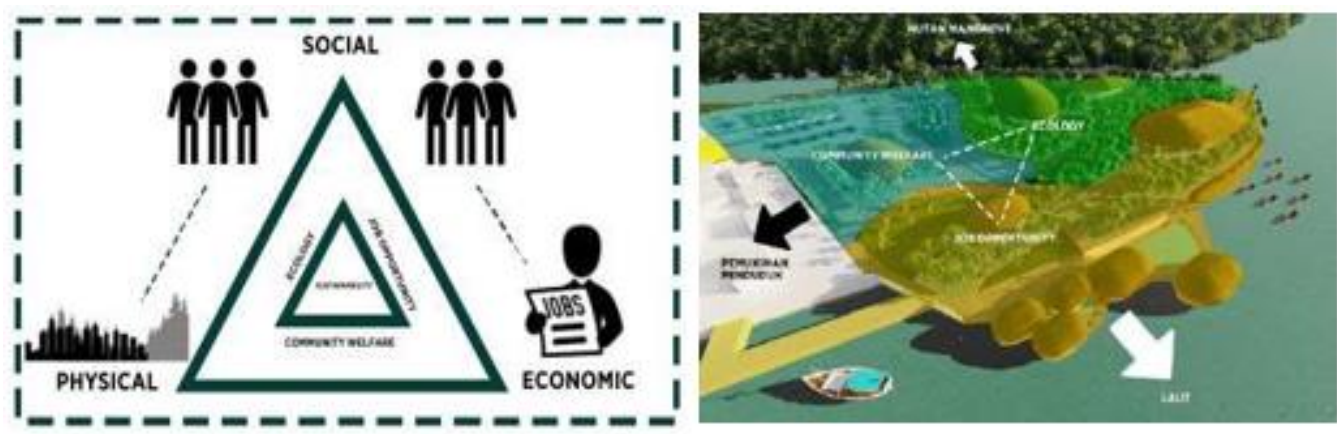

Gambar 5: Analogi Konsep Tri Axis

Sumber : Pribadi,2021

Penghubung ketiga zona merupakan sirkulasi utama, sedang persilangan dari Tri Axis menghasilkan titik tengah sebagai lokasi bangunan pengelolaan mangrove. yang diartikan sebagai tujuan dari proyek yaitu sustainability. Tujuan utama dalam penyusunan program proyek ini adalah untuk mewadahi konservasi dan pengembangan wisata mangrove. Dilengkapi dengan adanya sekolah mangrove untuk anak-anak nelayan untuk pengembangan diri. Untuk menunjang ekowisata, fasilitas ini dilengkapi dengan area food court resto di area wisata. Keunikan dari foocourt ini adalah dikhususkan untuk menjual aneka kuliner khas Muara Angke.

\section{Konsep Bangunan}

Mengambil dari biomorfik arsitektur, bentuk bangunan merupakan analogi hutan mangrove, dan analogi dari silus kehidupan masyarakat di Muara Angke. Sehingga bentuk massa bangunan pada fasilitas ekowisata didominasi bentuk oval agar selaras dengan lingkungan mangrove dan mencerminkan ciri karakteristik lokal.
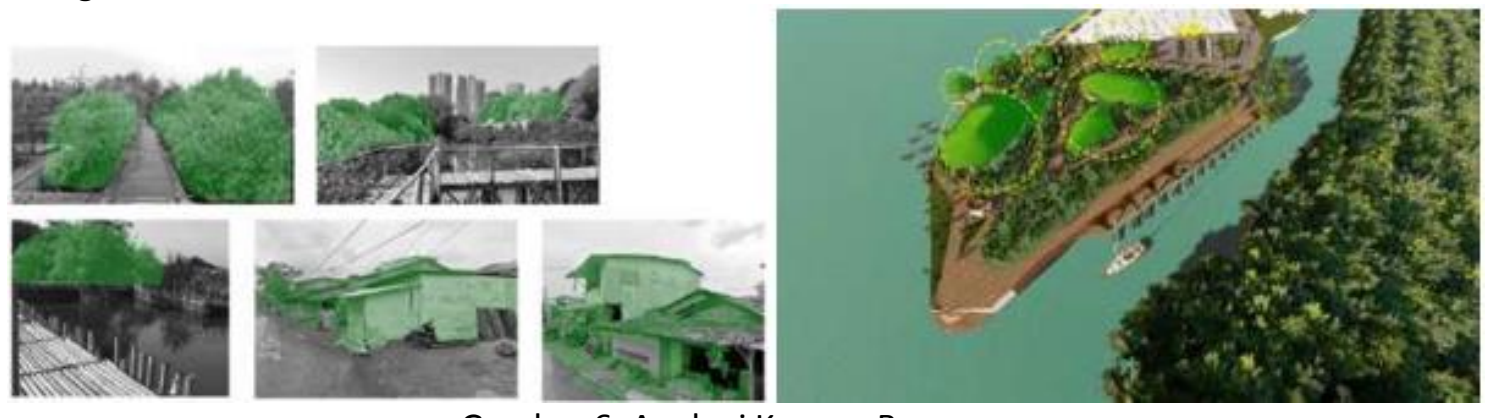

Gambar 6: Analogi Konsep Bangunan

Sumber : Pribadi,2021

\section{Program}

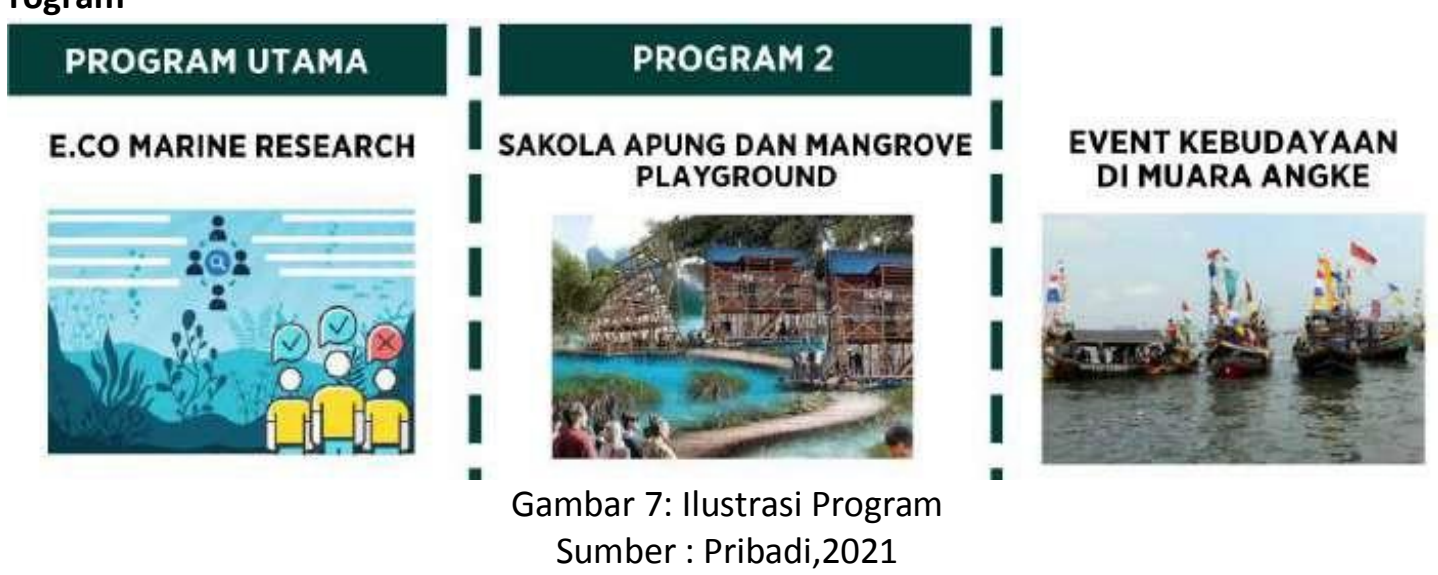


Protek Ecowisata Mangrove di Muara Angke ini mempunyai beberapa program utama sebagai berikut:

- Eco Marine Research : Workshop dan konsultasi ekosistem mangrove dengan masyarakat lokal,workshop untuk membantu nelayan dalam mengolahdan menjual hasil tangkapan ikan, dan juga area penelitian komunitas untuk pelestarian mangrove untuk inovasi-inovasi terbaru untuk diterapakan di Omah Mangrove.

- Sakola Apung : Sekolah untuk anak-anak nelayan yang berfokus pada pelatihan mental dan interaksi penduduk lokal dalam menghadapi pengunjung. Targetnya lebih ke anak- anak nelayan umur 10-18 tahun .(Pelatihan pertunjukan Nadran,pelatihan show agar menarik minat pengunjung untuk menonton).

- Eko Tourism Mangrove : Pengolahan konservasi mangrove dimanfaatkan menjadi tempat wisata yang dilengkapi dengan fasilitas foodcourt, area wisata laut, dan juga walkway untuk mengelilingi hutan mangrove. Area untuk menikmati hutan mangrove dan merasakan ciri khas dan jati diri dari area Muara Angke.
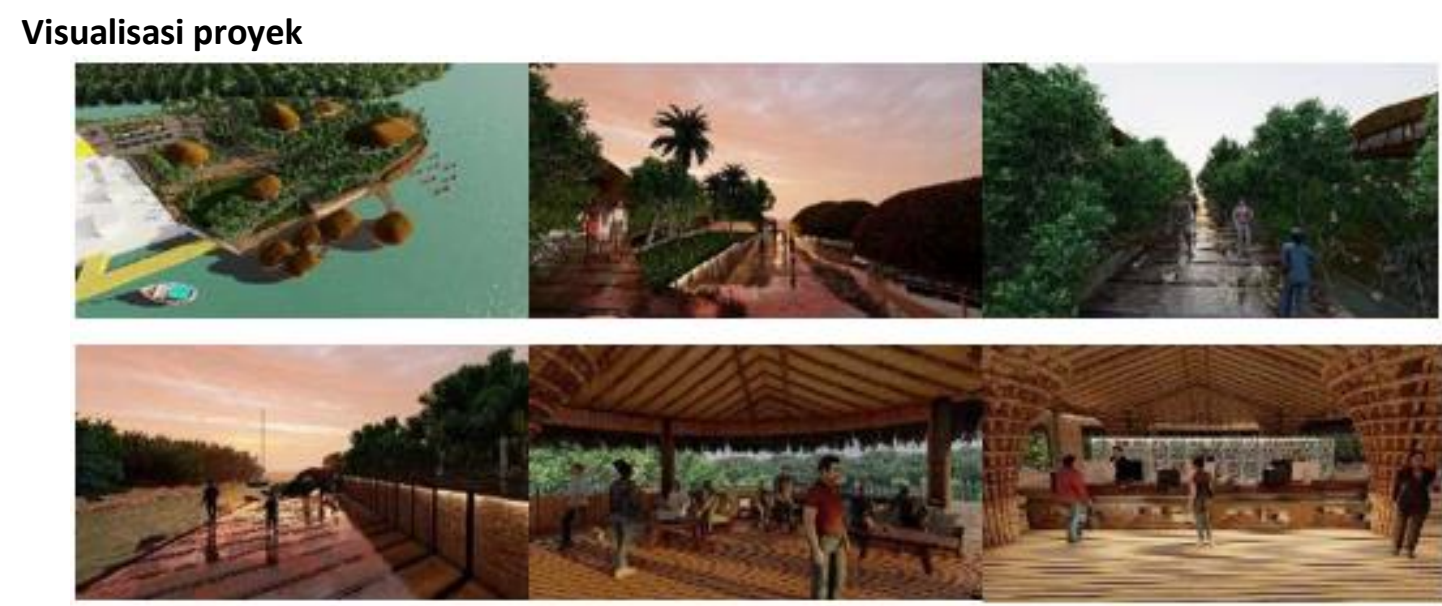

Gambar 8: Perspektif Exterior dan Interior Sumber : Pribadi,2021

Sistem Pengairan Pada Area Konservasi Mangrove

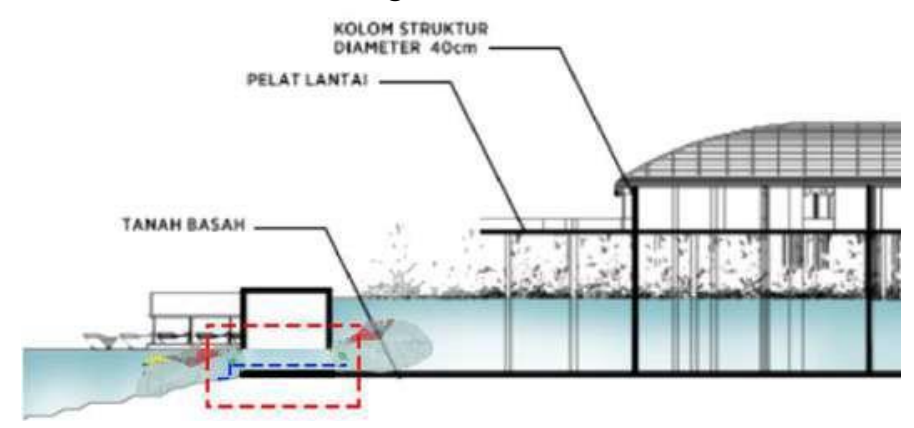

Gambar 9: Potongan sistem pengairan air

Sumber : Pribadi, 2021

Air payau sebelum masuk ke dalam site akan melalui pintu air dan akan melewati proses filtrasi agar sampah dan kandungan yang berbahaya bagi pertumbuhan mangrove dan disaring. Pintu air buka tutup atau klep otomatis sesuai dengan pergerakan tekanan air sebagai akibat dari 
aliran pasang surut air, hal ini dimaksudkan pada saat kondisi pasang pintu air akan menutup oleh gerakan air pasang dan pada saat kondisi air surut pintu akan terbuka akibat gerakan air dalam blok (outlet). Pintu air buka tutup atau klep otomatis sesuai dengan pergerakan tekanan air sebagai akibat dari aliran pasang surut air, hal ini dimaksudkan pada saat kondisi pasang pintu air akan menutup oleh gerakan air pasang dan pada saat kondisi air surut pintu akan terbuka akibat gerakan air dalam blok (outlet).

\section{Proses Filtrasi Air}

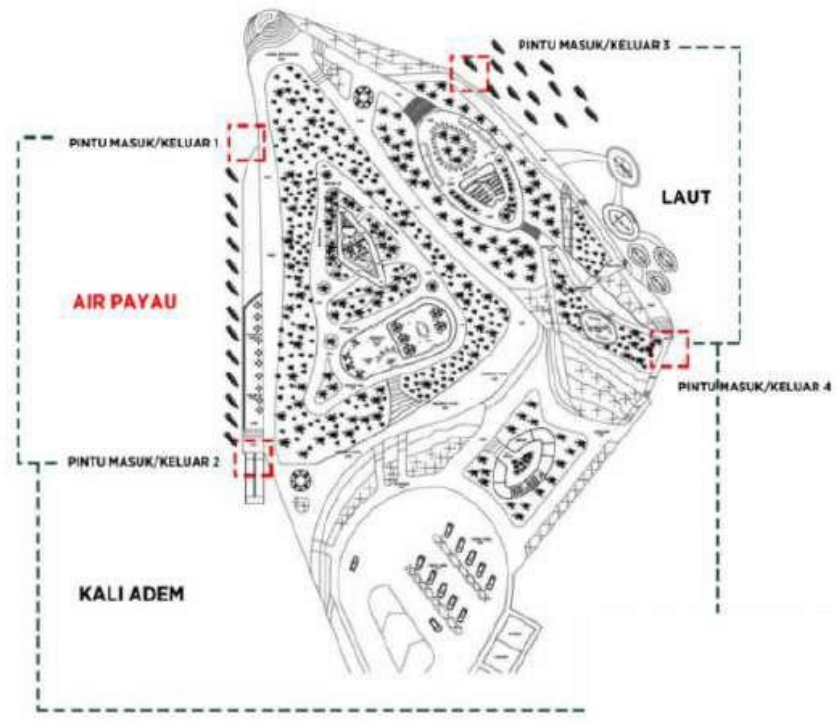

Gambar 10: llutrasi pintu air

Sumber : Pribadi, 2021

Terdapat 4 titik untuk aliran air masuk dan keluar air payau yang berasal dari Kali Adem.

\section{Teknologi filtrasi air laut}
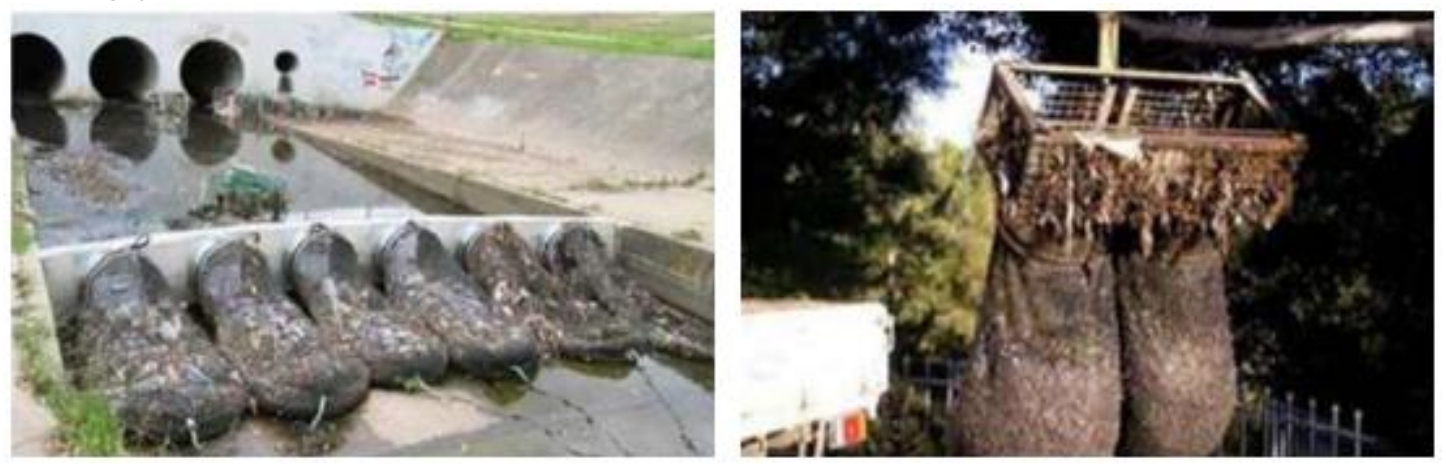

Gambar 11: Contoh llustrasi Filtrasi Sampah

Sumber : https://hai.grid.id/read/071246681/simpel-tapi-berfaedah-ini-cara-australia-atasisampah-plastik-di-air?page=all

Sistem filtrasi dari sampah diadopsi dari cara Australia dalam menyaring sampah plastik pada saluran air. Sistem ini menggunakan Jaring-jaring raksasa dan cara ini berhasil dan cukup sederhana untuk diterapkan. Intesitas sampah plastik di Kali Adem yang cukup tinggi. Pertimbangan ini cocok untuk di terapkan pada sirkulasi keluar masuk dari air kolam mangrove supaya mangrove terlindung dari sampah plastik. Sampah plastik yang terkumpul akan dijual ke pengepul dan mendapat tambahan penghasilan. 


\section{KESIMPULAN DAN SARAN}

\section{Kesimpulan}

Konsep Tri Axis dan Biomorfik merupakan ide yang dapat mencapai sustainability, tujuannya adalah agar fasilitas ekowisata ini akan terus berkembang seiring berkembangnya zaman. Massa-massa bangunan juga akan bertambah dan menyebar seiring adanya fungsi-fungsi yang inovatif. Ekowisata dan konservasi mangrove juga akan berkembang ruang lingkup areanya, tidak hanya berfokus di area yang sudah dirancang saja. Untuk masa depan diharapkan akan muncul area-area wisata baru yang tercipta dari perkembangan bangunan ini. Proyek ini akan menyebar dan menggambarkan jati diri dari masyarakat dan hutan mangrove Muara Angke.

\section{Saran}

Saran untuk pengembangan studi dan desain yaitu sebagai berikut :

a. Para komunitas-komunitas mangrove dan kelautan perlu melihat existensi dari hutan mangrove Muara Angke karena di sana merupakan area yang memiliki potensial namun belum diperhatikan secara serius.

b. Kawasan Muara Angke diharapkan akan terus berkembang dan inovatif namun tetap mempertahankan jati diri dan ciri-ciri lokalitas masyarakat nelayan yang dapat hidup secara berkelanjutan.

\section{REFERENSI}

Andika, W. (2021) Nelayan Muara Angke dan reklamasi

Dari https://www.antaranews.com/berita/2062350/nelayan-muara-angke-berharap-proyekreklamasi-berlanjut-kembali

Hasyasce, 2017 . Definisi Arsitektur Biomorfik Dari http://hasyapudjadi.blogspot.com/2016/01/arsitektur-biomorfik.html

Hidayatulah,Taufiq. 2020. Reklamasi yang akan menyingkirkan nelayan

Dari https://lokadata.id/artikel/reklamasi-jakarta-yang-menyingkirkan-nelayan

Jamal, T. and Jamrozy, U. (2006). Collaborative networks and partnerships for Integrated destination management. In Tourism Management Dynamics. D. Buhalis and C. Costa (eds.), Amsterdam: Elsevier, pp. 164-172.

Jaya, Adam Pasuna. (2014). Alternatif Kebijakan Kompensasi Nelayan Muara Angke Akibat Jakarta Coastal Defence Strategy. Jurnal Perencanaan Wilayah dan Kota A V2N2 Institut Teknologi Bandung.

Oddav (2021). Pengertian fauna dan ekosistem mangrove dari Dari https://kumparan.com/mutajahidin-salas/pengertian-fauna-dan-fungsi-ekosistem-hutanmangrove/full

Orams, Mark B. 1995. Towards a More Desirable Form of Ecotourism. In Tourism Management, Vol. 16, No. 1, pp. 3-8. Great Britain: Elsevier Science Ltd.

Sutanto, A. (2021). Dromos-oikos. Kuliah Stupa 8.32. Prodi Arsitektur Universitas Tarumanagara. Sutanto, A. 2021. Peta Metode Desain. E-book. Prodi Arsitektur Universitas Tarumanagara. Swarbrooke, John. 1999. Sustainable Tourism Management. New York: CABI Publishing.

Sri, Y. (2012). Kajian Penerapan Konsep Ekologi Arsitektur sebagai Metode Perancangan Pembangunan Berkelanjutan dalam Manajemen Pengelolaan Iklim di Daerah Tropis dari http://eprints.uns.ac.id/12832/1/2. sri Yuliani.doc

Sulistyawati, L (2020). Mangrove yang tercemar oleh sampah Dari https://www.republika.co.id/berita/qeumn7384/417-kilogram-sampah-kotori-mangrove- angke

Vanya, K. ( 2021) Definisi ekologi https://www.kompas.com/skola/read/2021/04/16/163119269/ekologidefinisi-ruang-lingkup- asas-dan-manfaatnya?page=all

Yafnidawaty (2020). Definisi metode penelitian Dari https://raharja.ac.id/2020/10/26/perbedaan-metodologi-penelitian-dan-metodepenelitian/ 